\title{
Acidente ofídico em ovinos causado por Bothrops jararaca $^{1}$
}

\author{
Carlos Hubinger Tokarnia ${ }^{2 *}$, Marilene de Farias Brito ${ }^{3}$, Pedro Malafaia ${ }^{2}$ \\ e Paulo Vargas Peixoto ${ }^{2}$
}

\begin{abstract}
Tokarnia C.H., Brito M.F., Malafaia P. \& Peixoto P.V. 2008. [Snake bite accident in sheep by Bothrops jararaca.] Acidente ofídico em ovinos causado por Bothrops jararaca. Pesquisa Veterinária Brasileira 28(12):643-648. Projeto Sanidade Animal Embrapa/ UFRRJ, Seropédica, Rio de Janeiro 23890-000, Brazil. E-mail: tokarnia@ufrri.br

The occurrence of a snake bite accident in a herd of mixed Bergamascia sheep in the county of Miguel Pereira, State of Rio de Janeiro, is reported. Four adult sheep were bitten in the head by Bothrops jararaca within a short period of time. Their head was severely swollen, but the general state of them was good. One of the sheep was euthanasied. Masssive hemorrhages were found beneath the skin, which extended to the neck. Histologically, the subcutaneous hemorrhages infiltrated the adjacent muscles. In areas where the hemorrhages were more intense they caused separation of muscle fibers, some of which had a hyaline aspect. Differences in the occurrence of edema/ hemorraghes and necrosis in snake bite accidents, caused by various snake species in different animal species, are discussed.
\end{abstract}

INDEX TERMS: Snake bites, Bothrops jararaca, sheep.

RESUMO.- Relata-se a ocorrência de um acidente ofídico em um rebanho de ovinos, mestiços da raça Bergamascia, no município de Miguel Pereira, Estado do Rio de Janeiro. Quatro ovelhas adultas, com cerca $35 \mathrm{~kg}$ de peso, foram picados na cabeça por um exemplar de Bothrops jararaca dentro de curto espaço de tempo. Os animais apresentaram a cabeça muito tumefeita, mas o estado geral era bom. Um ovino foi eutanasiado. Verificou-se que a tumefação da cabeça era causada por hemorragia embaixo da pele, que se estendia ao pescoço. Histologicamente foi verificada na face, hemorragia maciça, principalmente no tecido subcutâneo, com infiltração de hemácias no tecido muscular adjacente, que em áreas onde era mais intensa, provocou afastamento entre as fibras musculares, algumas com aspecto hialinizado. Discute-se a causa das diferenças sobre a ocorrência de edema/hemorragia e necrose no envenenamento causa-

\footnotetext{
${ }^{1}$ Recebido em 13 de junho de 2008.

Aceito para publicação em 19 de julho de 2008.

${ }^{2}$ Departamento de Nutrição Animal e Pastagem, Instituto de Zootecnia, Universidade Federal Rural do Rio de Janeiro (UFRRJ), Seropédica, RJ 23890-00, Brasil. *Autor para correspondência: tokarnia@ufrrj.br

${ }^{3}$ Departamento de Epidemiologia e Saúde Pública, Instituto de Veterinária, UFRRJ, Seropédica, RJ.
}

do pelas diversas serpentes do gênero Bothrops nas diferentes espécies animais.

TERMOS DE INDEXAÇÃO: Picada de cobra, acidente ofídico, Bothrops jararaca, ovinos.

\section{INTRODUÇÃO}

Há poucos relatos na literatura sobre acidentes ofídicos fatais em animais de produção no Brasil. Em revisão verificou-se que só havia dois diagnósticos fundamentados de envenenamentos fatais por Bothrops spp. em bovinos e nenhum por Crotalus spp. (Grunert 1967, Grunert \& Grunert 1969, Menezes 1995/96). Detalhes sobre esses casos constam na revisão de Tokarnia \& Peixoto (2006).

Em outros animais de fazenda há a descrição de Méndez \& Riet-Correa (2007) sobre um acidente ofídico em ovinos e caprinos causada por Bothrops neuwiedi no Estado do Rio Grande do Sul. De setembro de 1988 a janeiro de 1989 em um rebanho de 135 ovinos, 22 (16,3\%) foram picados por cobras e $11(8,1 \%)$ morreram. Antes da tosquia, as ovelhas foram picadas na cabeça, porém depois dela (em dezembro) a maioria das picadas ocorreu nos membros e no abdômen. Quando mordidas na cabeça, as ovelhas apresentavam severo edema na ca- 
beça e no pescoço, que ocasionalmente se estendia à região esternal. Quando picados nos membros, os animais mostravam acentuada manqueira e edema, que às vezes se estendia ao abdômen e tórax. Após o corte da lã, às vezes as marcas dos dentes das serpentes ainda eram perceptíveis. A morte, que era mais comum em cordeiros e animais jovens, ocorria em 24 a 48 horas após a picada. Em alguns dos animais sobreviventes, necrose e desprendimento da pele foram observados. Não foram feitas necropsias. Adicionalmente, nessa mesma oportunidade, em um grupo de cinco caprinos, um foi picado e morreu.

Foi relatado um acidente ofídico, provavelmente por Bothrops, em um eqüino de um mês de idade, no município de Pelotas, Rio Grande do Sul. (Raposo et al. 2000/ 2001). Observaram-se edema na região peitoral e dos membros anteriores. Na orelha esquerda havia duas perfurações paralelas separadas por $1,8 \mathrm{~cm}$. À necropsia verificaram-se petéquias e sufusões nas serosas, nos intestinos, no estômago, no fígado, no baço, no pulmão e no trato gênito-urinário. Havia hemorragias na musculatura adjacente à picada, "edema cerebral" e rins aumentados de volume e congestos. O exame histológico revelou congestão e hemorragias acentuadas na maioria dos órgãos, necrose muscular e necrose tubular aguda no rim.

Realizamos uma consulta através de um questionário dirigido a colegas patologistas e clínicos veterinários que atuam em diversos Estados do país, sobre suas experiências com acidentes ofídicos em animais domésticos.

Em relação a bovinos, todos responderam que nos muitos anos de atividade, à base do quadro clínico-patológico, em nenhum caso estabeleceram o diagnóstico de acidente ofídico como causa de morte, o que também está de acordo com a nossa experiência. Através da consulta somente obtivemos informações sobre alguns casos suspeitos de acidente ofídico (detalhes sobre esta consulta e sobre a nossa experiência constam na revisão acima mencionada). Posteriormente obtivemos históricos de Ollhoff (2005) sobre três possíveis casos de envenenamento ofídico em bovinos encontrados mortos (dois casos causados por Bothrops, um em Curitiba, PR, outro em São Carlos, SP, e um caso determinado por Crotalus no município de São Carlos, SP). No acidente crotálico o autor refere sinais de picada na barbela, sem outras alterações à necropsia; no possível envenenamento botrópico, no Paraná, menciona extensas hemorragias subcutâneas e no peritônio. No outro caso que ocorreu em São Paulo, verificou dois pontos de sangramento no muflo e aumento de volume da cabeça (nesse último caso não foi feita necropsia).

No que se refere a ovinos, Barros (2008) informa sobre um caso de envenenamento fatal que foi registrado no Departamento de Patologia da Universidade Federal de Santa Maria, em 2007. Tratava-se de um animal com 18 meses de idade, fêmea, procedente do município de Santa Maria. De acordo com o histórico clínico, o ovino foi encontrado no campo com acentuado edema na face, sangramento nasal e ocular bilateral e duas lesões perfurantes na face, com distância de $2 \mathrm{~cm}$ entre elas. De acordo com o laudo de necropsia, foi constatado edema da cabeça e, ao corte, o tecido subcutâneo era acentuadamente edematoso e hemorrágico. A hemorragia se estendia até a porção ventral do pescoço, à altura da entrada do tórax. Os músculos da face estavam hemorrágicos, nos locais correspondentes às lesões de pele e tecido subcutâneo. A região peri-orbital e as pálpebras apresentavam acentuado edema e havia coágulos de sangue nas cavidades orbitárias. Havia áreas de hemorragia no epicárdio e o endocárdio, principalmente do ventrículo esquerdo, apresentava área focalmente extensa de hemorragia. No interior da traquéia havia espuma rósea. $\mathrm{Na}$ mucosa intestinal havia múltiplas petéquias ao longo de toda a parede. O exame histológico do lábio, das bochechas e da pálpebra revelou, na derme, área focalmente extensa de hemorragia, que se estendia até as camadas mais profundas e atingia os músculos adjacentes. No miocárdio foram constatadas áreas multifocais a coalescentes de hemorragia e nos interstícios moderado edema que separava as fibras musculares.

Em relação aos eqüídeos Barros (2008) informa sobre um caso de envenenamento fatal em um eqüino que foi registrado no Departamento de Patologia da Universidade Federal de Santa Maria; tratava-se de um animal com 3 anos de idade, macho, procedente do município de São Sepé. De acordo com o histórico clínico, o animal apresentou edema unilateral no focinho e na cabeça. Caminhava com os membros posteriores "travados", apresentou incoordenação, debateu-se e morreu com cerca de 12 horas de evolução do quadro clínico. Na necropsia foram constatados edema e hemorragia subcutâneos afetando principalmente o lado esquerdo da cabeça e do pescoço, acentuadas hemorragias epicárdicas e endocárdicas, múltiplas petéquias na serosa intestinal e na superfície capsular do rim, hemorragias acentuadas entre as fáscias musculares e entre os feixes de fibras em grandes áreas musculares. O exame histológico revelou hemorragias interfasciculares focalmente extensas acentuadas e hemorragias multifocais no pulmão, baço, linfonodos e timo; no fígado foi verificada leve degeneração vacuolar centrolobular multifocal moderada e no rim grande quantidade de cilindros hialinos intratubulares que preenchiam a maioria dos túbulos e hemorragia peritubular e periglomerular multifocal moderada.

Driemeier (2003) informa que realizou necropsia de um cavalo procedente do município de Taquara, Rio Grande do Sul, que acredita ter sido caso de picada de cobra, provavelmente Bothrops. O cavalo morreu numa área de lavoura de arroz antiga, onde havia morrido outro animal em condições semelhantes e no mesmo local, dias antes. Tinha edema acentuado com hemorragias na cabeça e sangue não-coagulado no abdômen. Ao exame histológico apresentou trombos hialinos em vários órgãos.

Lemos (2004) informa que viu dois casos de acidente ofídico em eqüinos, não-fatais. Os animais se recupera- 
ram. Também Lemos (2008) comunica, que foi informado sobre um acidente por jararaca em um eqüino da fazenda escola, no município de Campo Grande, Mato Grosso do Sul. Este cavalo apresentou severo edema e claudicação e foi levado para o hospital veterinário. No dia seguinte apresentou, no local do edema, exsudação de líquido serossanguinolento. Foi tratado com soro antiofídico e antiinflamatórios (corticosteróides) e recuperou-se após perder grande parte do tecido da área afetada que necrosou. Ainda acrescenta: "Colegas que têm fazendas no pantanal relatam, com certa freqüência, mortes em eqüinos que atribuem a acidentes ofídicos, mas não têm diagnósticos comprovados. Um professor da nossa faculdade informou que teve um acidente com morte em um cavalo de sua propriedade, mas não realizou necropsia. $\mathrm{Na}$ verdade os dados sobre este problema são muito imprecisos em nosso Estado".

Santos (2004) informa que necropsiou um eqüino, procedente do município de Cuiabá, Mato Grosso, em que fez o diagnóstico de morte por picada de cobra. Verificou edema na região nasal, pontos de inoculação identificável na narina esquerda, epistaxe, hemorragias na gengiva, tempo de coagulação aumentado e sangramentos pela pele.

Ainda há dados obtidos através de levantamentos realizados por diversos autores, sem o fornecimento de pormenores:

1) Em estudo retrospectivo realizado a partir de prontuários de animais atendidos de 1972-1989 no Hospital Veterinário da Faculdade de Medicina Veterinária e Zootecnia (FMVZ) da Unesp-Botucatu, Bicudo \& Biondo (1989) encontraram 149 registros de acidentes ofídicos, dos quais 128 se referem a serpentes do gênero Bothrops, 11 ao gênero Crotalus e 10 a acidentes sem identificação. Desses envenenamentos, 103 ocorreram em caninos, 22 em eqüinos, 17 em bovinos, quatro em caprinos, dois em gatos e um em suíno. Infelizmente não são fornecidos dados sobre letalidade em cada espécie animal, quais foram as serpentes envolvidas em relação a cada espécie animal, nem há informações sobre os quadros clínico-patológicos ou como foram feitos esses diagnósticos.

2) De acordo com um levantamento de 1260 boletins de notificação do Instituto Butantan, referentes ao período de 19051941 , os eqüinos foram os mais acometidos pelas picadas de serpentes, seguidos pelos cães e bovinos. Os cães foram mais freqüentemente atingidos pelas picadas de serpentes do gênero Bothrops. São apresentadas diversas fotografias do quadro clínico-patológico de acidentes ofídicos em eqüinos, cães e bovinos, sem fornecimento de pormenores. (Melo et al. 2004)

3) De acordo com levantamento realizado no Hospital Veterinário de Botucatu, nos últimos dez anos foram registrados 100 acidentes ofídicos, dos quais 8 eram provenientes de picadas por serpentes do gênero Crotalus, enquanto que a maioria (92) dos casos estava relacionada a serpentes do gênero Bothrops. Os cães foram os animais mais afetados (cerca de 73) por esses acidentes. As demais espécies envolvidas foram bovinos e eqüinos. Não são fornecidos pormenores. (Collicchio et al. 2002).

No presente estudo, apresentamos os dados sobre a ocorrência do envenenamento em quatro ovinos por picada de Bothrops jararaca no Estado do Rio de Janeiro.

\section{MATERIAL E MÉTODOS}

O estudo consistiu na obtenção do histórico sobre o acidente na fazenda localizada no município de Miguel Pereira, Estado do Rio de Janeiro e no exame clínico das quatro ovelhas adultas afetadas, que eram mestiças da raça Bergamascia, com aproximadamente $35 \mathrm{~kg}$. Adicionalmente, no dia seguinte à picada foi feita eutanásia em uma delas para realização de necropsia. Três dias depois novo exame clínico foi realizado nos três animais restantes afetados. Durante a necropsia foram coletados fragmentos dos diversos órgãos em formol a $20 \%$ para exames histopatológicos. O ofídio foi encaminhado ao Dr. Anibal Melgarejo, no Instituto Vital Brazil, RJ, para identificação.

\section{RESULTADOS}

$\mathrm{O}$ acidente ocorreu em uma fazenda com cerca de 300 ovinos, no município de Miguel Pereira, Estado do Rio de Janeiro. Em 17.1.2008, às 7:30 horas, quando chegou, o funcionário observou que três ovelhas, de um total de 28, que estavam na mesma baia, apresentavam a cabeça muito inchada. Logo a seguir viu uma jararaca, muito agressiva, picando uma quarta ovelha, que também rapidamente apresentou a cabeça volumosa. Matou a cobra esmagando a sua cabeça. A cobra tinha $101 \mathrm{~cm}$ de comprimento e foi identificada como Bothrops jararaca.

Ao exame dessas quatro ovelhas em 18.1.2008, às 9:horas, verificamos que estavam com a cabeça bastante tumefeitas (Fig.1). De acordo com o tratador, as oveIhas já estavam menos inchadas do que no dia anterior. Elas estavam ativas, não demonstravam sinais de dor e se alimentavam de capim picado. Uma ovelha (Ovino 39) tinha leve sangramento pelas narinas e pela boca e, à uma observação mais cuidadosa, percebia-se um pequeno furo no lado esquerdo da cabeça, posterior à comissura labial, com presença de uma pequena gota de sangue coagulado. Suspeitou-se que fosse lesão provocada pela picada. Nas outras três ovelhas (Ovinos 3, 40 e 55) não se observou perfurações que pudessem ser atribuídas à picada da cobra.

Procedeu-se a eutanásia do Ovino 39. À depilação da lã da cabeça, notou-se intensa coloração vermelha da pele em toda área tumefeita. Confirmou-se a presença da perfuração vista no animal vivo. Ao corte da pele e do tecido subjacente, verificou-se que o aumento de volume da cabeça era devido ao acúmulo de sangue coagulado de coloração variando de vermelha escura a vermelho mais claro, com espessura de até um centímetro sob a pele, e que se estendia à parte superior da região peri-traqueal/ peri-esofagiana (Fig.2). Além dessa lesão foram constatadas somente equimoses no endocárdio esquerdo.

Ao exame histopatológico (SAP 31154/55/56) verificouse grande derrame de sangue no tecido subcutâneo da face e do pescoço. Na camada muscular adjacente havia infiltração de hemácias, que em áreas onde era mais intenso, provocou afastamento entre as fibras musculares, algumas com aspecto hialinizado (Fig.3-4). No linfonodo regional havia grande quantidade de hemácias drenadas.

Ao reexame clínico das três ovelhas restantes em 21.1.2008, às 9:00 h, verificamos que estavam normais e que a tumefação da cabeça tinha desaparecido comple- 

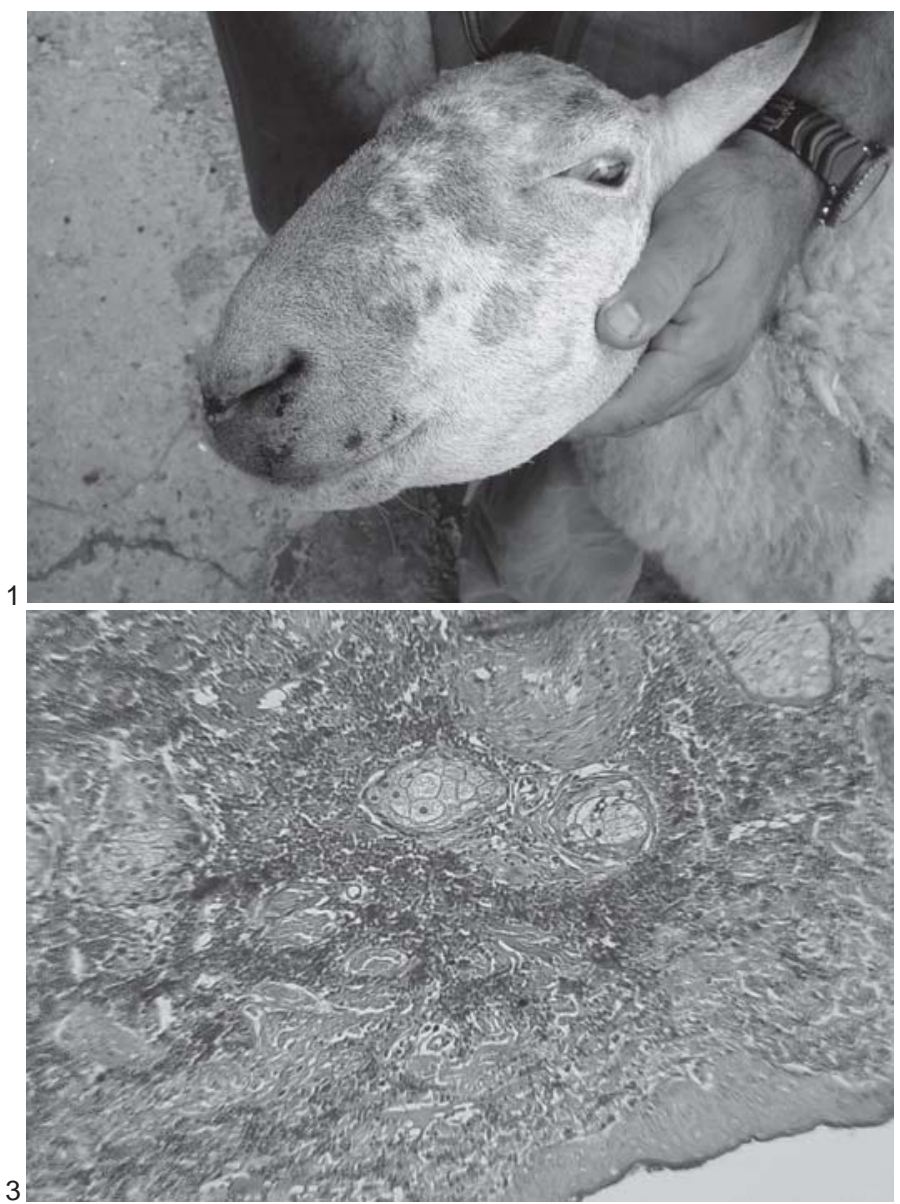

Fig.1. Acentuada tumefação da cabeça, no acidente ofídico por Bothrops jararaca (Ovino 40).

Fig.3. Grande derrame de sangue no tecido subcutâneo da face, no acidente ofídico por Bothrops jararaca (Ovino 39). HE, obj.10x.

tamente. O tratador informou que, em 19.1.2008 as oveIhas só estavam um pouco inchadas e que, em 20.1.2008, a lesão tinha desaparecido completamente, sem administração de qualquer medicamento.

\section{DISCUSSÃO}

O conjunto dos dados permite estabelecer o diagnóstico de acidente ofídico por Bothrops jararaca.

De acordo com estudos realizados por Rosenfeld \& Belluomini (1960), a média da quantidade total de veneno (MG) fornecida por $75 \%$ das serpentes da espécie $B$. jararaca na primeira extração é $65 \mathrm{mg}$. Para o bovino a dose letal, tanto por via intramuscular como subcutânea, é 1,0mg/ $\mathrm{kg}$; desse modo essa quantidade seria suficiente para causar a morte de um bovino de $65 \mathrm{~kg}$ (Araujo et al. 1963).

Araujo \& Belluomini (1960/62) verificaram experimentalmente maior sensibilidade do eqüino, ovino e bovino, ao veneno de ofídios, seguindo-se em ordem decrescen-
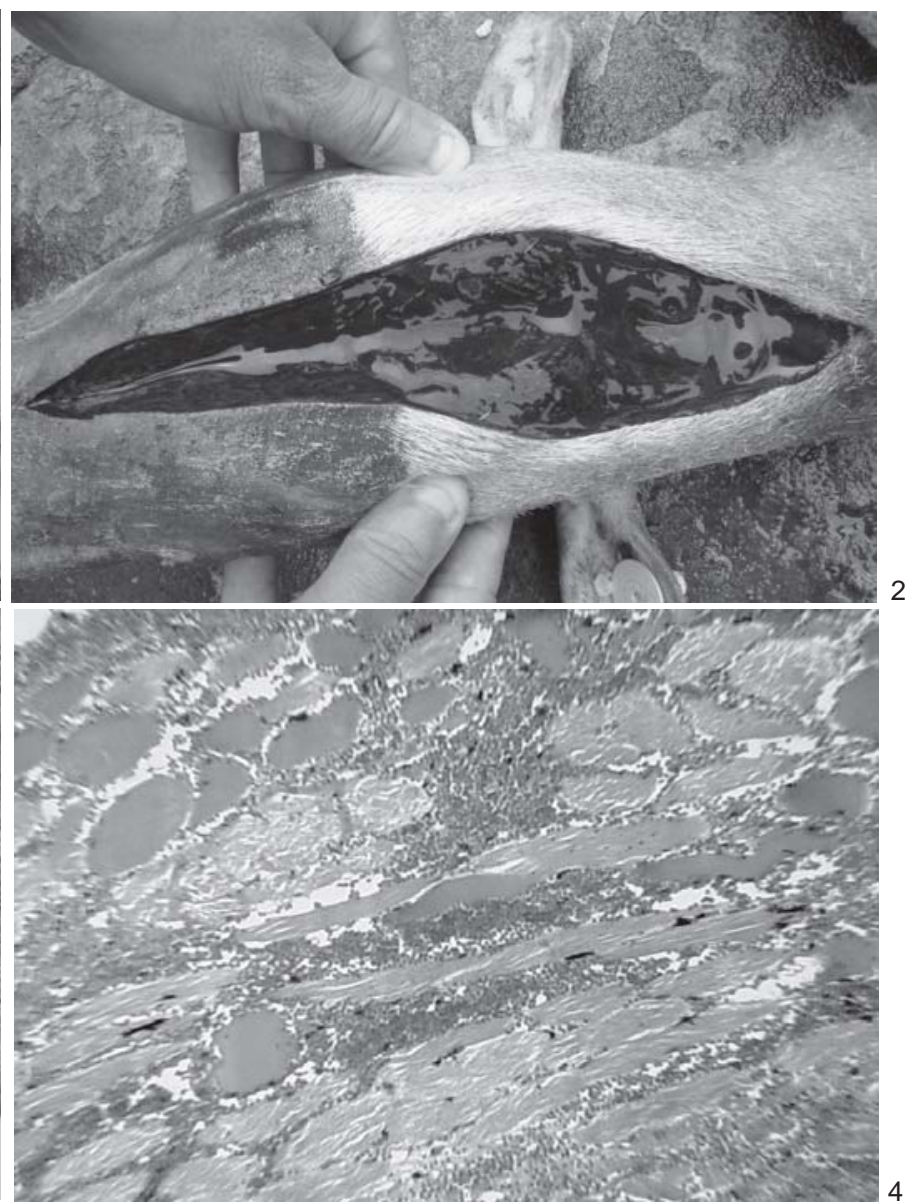

Fig.2. Hemorragia maciça embaixo da pele na região submandibular e do pescoço, no acidente ofídico por Bothrops jararaca (Ovino 39).

Fig.4. Infiltração de hemácias entre fibras musculares do tecido subcutâneo da face, algumas com aspecto hialinizado, no acidente ofídico por Bothrops jararaca (Ovino 39). HE, obj.10x.

te, caprino, cão, coelho, suíno, cobaio, comundongo, gato e hamster.

Pode-se admitir que o veneno da jararaca em questão poderia ter causado a morte de um ovino com até $65 \mathrm{~kg}$ de peso. Pelas informações do tratador a cobra estava agressiva. É provável que em cada picada tenha sido inoculado somente parte do veneno, o que explicaria o desfecho não-fatal das picadas nos ovinos. Dá suporte a esta suposição o fato de não se ter encontrado perfurações das picadas nas ovelhas, com uma exceção; aparentemente as picadas devem ter sido superficiais com inoculação de menos de 35mg por ovelha.

O quadro clínico-patológico verificado nos ovinos, e especialmente no ovino necropsiado, corresponde às verificadas no envenenamento por serpentes do gênero Bothrops.

Há diversas pesquisas baseadas na experimentação em animais sobre a ocorrência de edema/hemorragia e 
necrose no local da picada por serpentes do gênero Bothrops.

O aumento de volume no local da picada por serpentes de gênero Bothrops, em geral, é atribuído a edema.

Assim, em trabalho experimental com a inoculação intramuscular de venenos de diversas espécies de Bothrops em várias espécies animais (cavalo, boi, carneiro, cabra, porco, cão, gato, coelho, cobaio, rato, hamster e camundongo), foi verificado que os venenos botrópicos mostraram-se altamente ativos para formação de edema. (Araujo \& Belluomini 1960-62)

Em outros experimentos em bovinos, constatou-se que os venenos de Bothrops, independentemente da via inoculação, das doses usadas e do local da aplicação, produziram acentuado edema em todos os bovinos (Araujo et al. 1963).

No envenenamento por diversas espécies de Bothrops em bovinos, Novaes et al. (1986), induziram picadas na face e também na bochecha, e verificaram que os "edemas" mais intensos foram provocados pelas espécies Bothrops jararacussu, B. alternatus, B. atrox e B. moojeni; os menos intensos foram observados com as espécies $B$. jararaca e $B$. neuwiedi. Nos achados de necropsia esses autores relatam edema sero-hemorrágico.

Nos experimentos com Bothrops alternatus em bovinos, Caldas et al. (2008) verificaram que a tumefação no local da aplicação do veneno era devido a acentuadas hemorragias subcutâneas, quando a inoculação foi subcutânea e também no músculo quando a inoculação foi intramuscular, e não devido a edema.

Nos dois casos, um em ovino, outro em eqüino, verificados por Barros (2008) em Santa Maria, de acordo com a descrição e as fotos fornecidas, a tumefação era essencialmente hemorrágica.

Em relação à ocorrência de necrose no local da picada, no envenenamento por diversas serpentes do gênero Bothrops, Araujo \& Belluomini 1960/62, nos seus experimentos de inoculação intramuscular em várias espécies animais, verificaram poder necrosante de maior intensidade no veneno de Bothrops neuwiedi, seguido pelos venenos de B. jararaca, B. jararacussu e B. atrox, no cobaio, boi, cão, coelho e hamster; não houve formação de necrose no cavalo, carneiro, cabra, porco, gato, rato e camundongo. Os venenos de $B$. alternatus e $B$. cotiara não produziram necrose em nenhuma espécie.

Araujo et al. (1963) observaram necrose apenas através da inoculação dos venenos de Bothrops por via intramuscular, com exceção do veneno de $B$. cotiara, que não produziu necrose em nenhum animal. Por via subcutânea, os venenos botrópicos não produziram necrose, provavelmente devido à sua difusão por extensa área.

Caldas et al. (2008) observaram no exame histológico, além do quadro hemorragíparo, necrose muscular coagulativa, acompanhada de hemorragia, no entorno do local da inoculação nos animais que receberam o veneno por via intramuscular; essa lesão era discreta nos músculos próximos ao local de inoculação subcutânea.
Grunert (1967) e Grunert \& Grunert (1969) mencionam necrose em seus casos naturais de envenenamento por Bothrops em bovinos. Melo et al. (2004) trazem inseridos em seu texto sobre "Envenenamento botrópico" fotografias de um bovino com necrose na face maxilo-mandibular, sem fornecer dados sobre a espécie de Bothrops envolvida.

No presente caso o aumento de volume era devido a acentuada hemorragia embaixo da pele da face, que se estendia ao pescoço. Nos exames histopatológicos o aspecto hialinizado de algumas fibras musculares adjacentes ao tecido subcutâneo hemorrágico, ao nosso ver, foi causado pela compressão do sangue e não deve ser interpretado como necrose pela ação do veneno ofídico. Mesmo que a inoculação do veneno fosse por via intramuscular, em ovinos, de acordo com os experimentos de Araujo \& Belluomini (1960/62), não haveria necrose. Ao contrário, em diversas outras espécies de animais, $B$. jararaca causa necrose. A recuperação dos nossos ovinos foi rápida provavelmente devido a ausência de necrose. Caldas et al. (2008), também verificaram restabelecimento rápido, no único bovino experimental que não morreu; este animal tinha recebido o veneno por via subcutânea.

As diferenças sobre a ocorrência de edema/hemorragias e necrose no envenenamento botrópico tem, como se pode ver pelo acima exposto, como causa: 1) variação da ação do veneno de acordo com a espécie da serpente envolvida, 2) variação na reação das diversas espécies animais aos venenos das cobras, 3 ) variação da reação de acordo com a profundidade da aplicação do veneno (subcutâneo ou intramuscular), e 4) divergências nas interpretações. Deve-se acrescentar que freqüentemente a palavra edema é usada como sinônimo de tumefação (inchaço), independentemente da causa.

Acreditamos, com base nos dados disponíveis, que é preciso determinar melhor até que ponto envenenamentos ofídicos têm importância como causa de morte nos animais de produção no Brasil.

Agradecimentos.- Ao Dr. Anibal Rafael Melgarejo, Instituto Vital Brasil, Niteroi, pela identificação do ofídio.

\section{REFERÊNCIAS}

Araujo P. \& Belluomini H.E. 1960-62. Toxicidade de venenos ofídicos. I. Sensibilidade específica de animais domésticos e de laboratório. Mem. Inst. Butantan 30:143-156.

Araujo P., Rosenfeld G. \& Belluomini H.E. 1963. Toxicidade de venenos ofídicos. II. Doses mortais para bovinos. Arqs Inst. Biológico, São Paulo, 30:43-48.

Baialardi C.E.G., Raposo J.B., Stigger A.L., Andrade G.B. \& Raffi M.B. 1999. Ofidismo em eqüino: relato de caso. Anais 9ํㅡㄹ Enave, Belo Horizonte, p.148.

Barros C.S. 2008. Comunicações pessoais (Departamento de Patologia, Universidade Federal de Santa Maria. Santa Maria, RS).

Belluomini H.E. 1976. O que se deve saber sobre serpentes. Noticioso Rhodia-Mérieux 5(52):6-16.

Bicudo P.L. 1994. Acidentes ofídicos em Medicina Veterinária, p.375387. In: Barraviera B. (Ed.), Venenos Animais: uma visão integrada. EPUC, Rio de Janeiro. 
Bicudo P.L. \& Biondo A.W. 1989. Acidentes ofídicos atendidos no Hospital Veterinário da FMVZ, Unesp, Botucatu, SP, no período de 19721989: estudo retrospectivo (Não publicado). (Cit. Bicudo 1994).

Caldas S.A., Tokarnia C.H., França T.N., Brito M.F., Graça A.S., CoeIho C.D. \& Peixoto P.V. 2008. Aspectos clínico-patológicos e laboratoriais do envenenamento experimental por Bothrops alternatus em bovinos. Pesq. Vet. Bras. 28(6):303-312.

Collicchio R.C., Sakate M., Balaria M.R.S., Hataka A., Klein R.P., Viana L. \& Nogueira F.S. 2002. Relato de caso: alterações clínicas e laboratoriais conseqüentes à picada de cascavel (Crotalus durissus terrificus) em uma cadela gestante. Revta Clín. Vet., São Paulo, 7(40):45-48.

Driemeier D. 2003. Comunicação pessoal (Universidade Federal do Rio Grande do Sul, Porto Alegre).

Grunert E. 1967. Beobachtungen über Schlangenbissverletzungen bei grossen Haustieren in Süd-Brasilien. Dtsch. Tierärztl. Wochenschr. 74(20):531-532.

Grunert E. \& Grunert D. 1969. Beobachtungen von BothropsSchlangenbissverletzungen bei Rind und Pferd in Rio Grande do Sul, Brasilien. Vet.-Med. Nachrichten, Bayer, 1969, Heft 3:217-232.

Lemos R. 2004 e 2008. Comunicação pessoal (Universidade Federal de Mato Grosso do Sul, Campo Grande).

Melo M.M., Silva Jr P.G.P., Lago L.A., Verçosa Jr D. \& Habermehl G.G. 2004. Envenenamento botrópico, p.59-79. In: Araújo R.B., Oliveira
M.M.V. \& Nunes I.J. (Ed.), Serpentes Venenosas. Cad. Téc. Vet. Zootec. 44, FEPMVZ Editora, Belo Horizonte.

Méndez M.C. \& Riet-Correa F. 2007. Envenenamento botrópico, p.3138. In: Riet-Correa F., Schild A.L., Lemos R.A.A. \& Borges J.R.J. (Ed.), Doenças de Ruminantes e Eqüideos. Vol.2. $3^{\mathrm{a}}$ ed. Palotti, Santa Maria.

Menezes R.V. 1995/96. Ofidismo em bovinos. Arqs Esc. Med. Vet. UFBA 18(1):224-231.

Novaes A.P., Lucas S., Abe A.S., Fernandes W., Puorto G. \& Almeida I. L. 1986. Envenenamento botrópico em bovinos: tratamento opcional. Circ. Téc. 3, Embrapa-UEPAE, São Carlos, SP. 29p.

Ollhoff R.D. 2005. Comunicação pessoal (Pontifícia Universidade Católica do Paraná, Curitiba).

Raposo J.B., Méndez, M.C., Baialardi C.E.G. \& Raffi M.B. 2000/2001. Acidente ofídico em eqüino no sul do Brasil: relato de caso. Revta FZVA, Uruguaiana, 7/8(1):51-57.

Rosenfeld G. \& Belluomini H.E. 1960. Quantidades de veneno encontrado em serpentes venenosas do Brasil: dados comparativos para avaliação da mortalidade humana (Resumo). I Congresso de Zoologia, Museu Nacional, Rio de Janeiro (Não publicado). (Cit. Belluomini 1976)

Santos C.E.P. 2004. Comunicação pessoal (Universidade Federal de Mato Grosso, Cuiabá).

Tokarnia C.H. \& Peixoto P. 2006. A importância dos acidentes ofídicos como causa de mortes em bovinos no Brasil. Pesq. Vet. Bras. 26(2):5568. 